\title{
Developing a Technological Pedagogical Content Knowledge Framework for Science Education: Implications of a Teacher Trainers' Preparation Program
}

\author{
Athanassios Jimoyiannis \\ Department of Social and Educational Policy \\ University of Peloponnese, Korinthos, Greece
}

\author{
ajimoyia@uop.gr
}

\begin{abstract}
In this paper we describe a science teacher preparation program, implemented in Greece, aiming at ICT integration in classroom practice. The development of this teacher preparation program was guided by the various components of Technological Pedagogical Content Knowledge (TPACK) while attempting to meet the professional development needs of science teachers. We begin with an overview of this teacher preparation program. Next, we look specifically at program components and correlate them with the knowledge bases for science education in secondary schools, particularly Pedagogical Content Knowledge. This is followed by a review of recent research findings that report the impact of the teacher preparation program on teachers' views, perceptions and abilities to integrate ICT in science classroom. Finally, we draw on the apparent successes and challenges of the teacher preparation program to make suggestions regarding further applications of the construct of TPACK in science teacher preparation.
\end{abstract}

Keywords: Technological Pedagogical Content Knowledge, ICT in education, teacher development

\section{Introduction}

During the past decade a great discussion about the integration of Information and Communications Technologies (ICT) in education is evolving between researchers, policymakers and educators. A great amount of research has shown that the use of ICT as a learning tool, within meaningful contexts of learning can lead to significant educational and pedagogical outcomes in the schools and bring major benefits to both learners and teachers (see for example Webb (2005) and references therein). In this framework, ICT is perceived to be inherent to the educational reform efforts necessary for the 21 st century society while they produce fundamental changes in key as-

Material published as part of this publication, either on-line or in print, is copyrighted by the Informing Science Institute. Permission to make digital or paper copy of part or all of these works for personal or classroom use is granted without fee provided that the copies are not made or distributed for profit or commercial advantage AND that copies 1) bear this notice in full and 2) give the full citation on the first page. It is permissible to abstract these works so long as credit is given. To copy in all other cases or to republish or to post on a server or to redistribute to lists requires specific permission and payment of a fee. Contact 0HPublisher@InformingScience.org to request redistribution permission. pects of the nature of knowledge and the way students access it.

Even though educational policy directives have articulated clear and unambiguous statements about encouraging the use of ICT in the schools, the application of ICT in educational settings is rather peripheral acting, in most cases, as an 'add on' effect to regular classroom work (Jimoyiannis, 2009). Teach- 
ers, in general, are positive about students' development in ICT knowledge and skills and show great interest and motivation to learn about ICT (Jimoyiannis \& Komis, 2006). Even though they recognize the importance of introducing ICT in education, teachers tend to be less positive about their extensive use in the classroom and far less convinced about their potential to improve instruction. In most cases, they continue to use computers for low-level supplemental tasks such as word processing (lesson plans, worksheets, assessment tests, etc.) or getting information from the Internet (Jimoyiannis \& Komis, 2007; OFSTED, 2004; Waite, 2004).

Educational policy and consequent teacher preparation directives conceive ICT use in education not in terms of a special event or an extra tool supplemental to the traditional instruction but in terms of specific pedagogical dimensions. Existing research shows that technology seminars or workshops that focus on developing operational skills about general purpose and/or specific educational software do not help teachers understand how ICT could interact with particular pedagogies and enhance learning in specific subject matters (Jimoyiannis, 2008; Zhao \& Bryant, 2006). In addition, top-down imposed policy decisions and technocentric models for ICT adoption appear to be unresponsive to the teachers' perspectives, priorities, and classroom or general professional needs.

Since the 90's various models to explore and promote the process of integrating ICT into the curriculum have been proposed and established. Prominent among them were stage-based models for ICT adoption or integration (Rogers, 1995; Russell, 1996, Toledo, 2005). The key idea was the teachers' and students' development and movement from lower to higher levels of technology use and integration in educational settings. In this framework, most ICT teacher professional development initiatives tend to focus on technological aspects (i.e. how to use various tools) while pedagogical and instructional issues (i.e. why and how to use those tools to enhance learning) are often taken for granted (Jimoyiannis \& Komis, 2007). As a result the application of ICT in school settings has been driven more by the accordance of technology rather than the demands of pedagogy and didactics of subject matter.

The Technological Pedagogical Content Knowledge (originally TPCK, now known as TPACK) was firstly proposed by Mishra and Koehler (2006) to describe an integrated framework to clarify the critical parameters relating to technology integration in classroom settings, namely Content, Pedagogy and Technology. This framework does not consider the above three key elements in isolation, but rather in the complex relationships in the system they define. TPACK offers new perspectives and options for looking at a complex phenomenon like technology integration in the classroom. Moreover, it allows teachers, researchers, and teacher educators to move beyond oversimplified approaches that treat technology as an "add-on" instead to focus upon the connections among technology, content, and pedagogy as they play out in classroom contexts (Koehler \& Mishra, 2009).

The application of TPACK in teacher preparation initiatives is an under-investigated field and is of interest at the international level. Hence the present study aspires to shed light on critical aspects of TPACK framework in science education. This article describes a professional development model for science teacher trainers' aiming at teacher preparation for ICT integration in classroom practice. The development of this program was guided by the various components of the TPACK model while attempting to meet the professional development needs of science teachers.

\section{The Notion of Technological Pedagogical Content Knowledge}

Historically, teacher education has been focused on the content knowledge while general pedagogy was an added course, treated in isolation of the content, with emphasis on general pedagogi- 
cal classroom practices independent of subject matter. During the last decades, teacher education and professional development programs have shifted their focus from content knowledge to pedagogical knowledge related to specific content. The key argument is that knowledge of subject matter and general pedagogical strategies, though necessary, is not sufficient for capturing the knowledge of good teachers. The advanced idea of Pedagogical Content Knowledge (PCK), introduced by Shulman (1986), emphasizes on treating teachers' subject knowledge (Content) and pedagogy as mutually exclusive domains.

Built upon Shulman's (1986) work describing PCK, Mishra and Koehler (2006) proposed the concept of Technological Pedagogical Content Knowledge (TPACK) to describe teachers' understanding of the complex interplay between technology, content, and pedagogy. Three areas of knowledge constitute the core of this framework.

Content $(\mathbf{C})$ : Is the subject matter that is to be learned; $7^{\text {th }}$ grade biology, $8^{\text {th }}$ grade chemistry and $10^{\text {th }}$ grade physics are all examples of content that are different from one another.

Technology (T): Encompasses ICT technologies such as general purpose software, the Internet and related technologies, educational software, simulations, modeling tools, and more.

Pedagogy (P): Describes the collected practices, processes, strategies, procedures, and methods of teaching and learning. It also includes knowledge about the aims of instruction, assessment, and student learning.

The TPACK framework recognizes the complexity and interplay among the three constitutional elements of contemporary learning environments (see Figure 1). However, the TPACK approach goes beyond seeing these three knowledge bases in isolation. It emphasizes the connections and the complex relationships between those dimensions of knowledge (constitutional elements) while it defines three new areas of knowledge, namely Pedagogical Content Knowledge (PCK), Technological Content Knowledge (TCK) and Technological Pedagogical Knowledge (TPK).

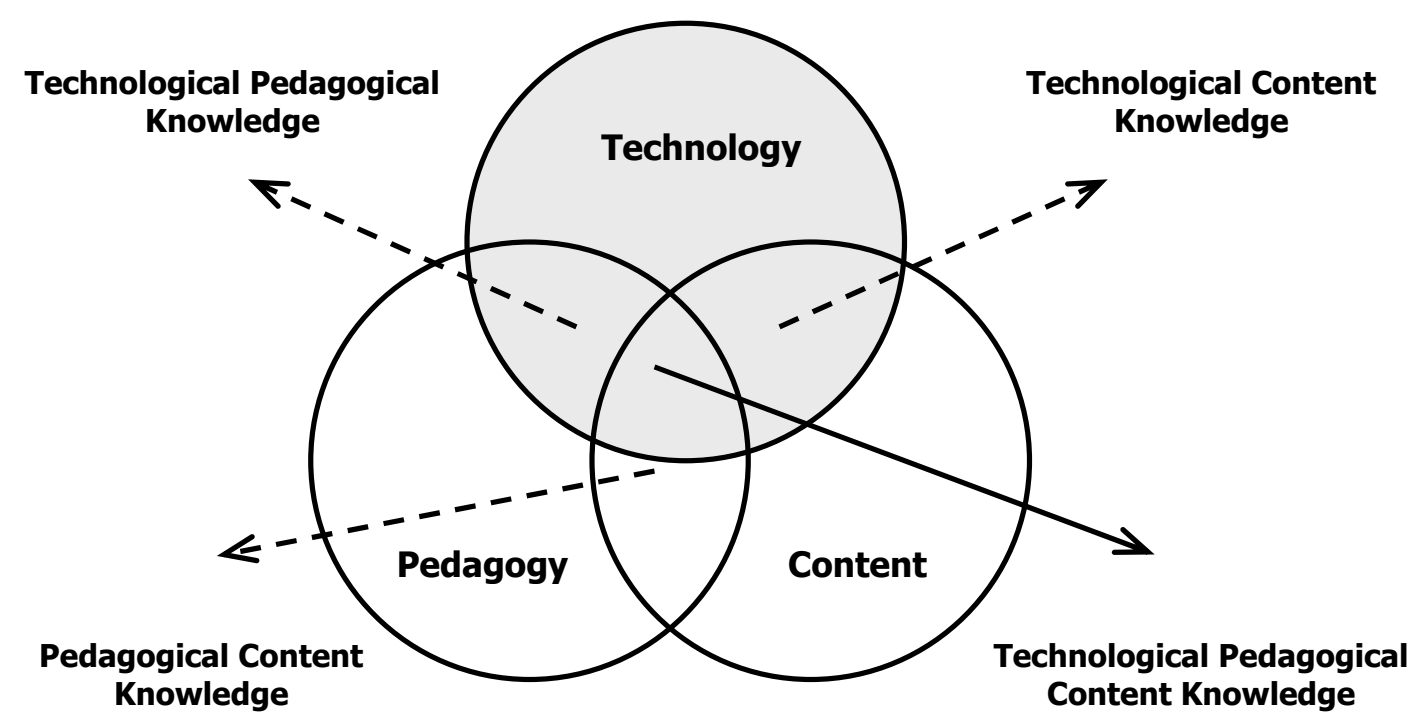

Figure 1. Technological Pedagogical Content Knowledge (adapted from Koehler et al. (2007) 
Pedagogical Content Knowledge (PCK): By considering Pedagogy (P) and Content (C) together we get Pedagogical Content Knowledge. According to Shulman (1986), PCK represents the knowledge of pedagogy that is applicable to the instruction of specific science content.

Technological Content Knowledge (TCK): Similarly, T and C taken together yield the construct of Technological Content Knowledge. This type of knowledge is useful for describing teacher's knowledge of how subject matter is transformed by the application of technology.

Technological Pedagogical Knowledge (TPK): T and P together describe Technological Pedagogical Knowledge which refers to a general understanding of the application of technology in education without reference to a specific content. It includes the knowledge of how technology can support specific pedagogical strategies and/or goals in the classroom.

Finally, if we jointly consider all three elements we get Technological Pedagogical Content Knowledge (TPACK). Koehler and Mishra (2006) argue that true technology integration demands understanding and negotiating the relationships between these three components of knowledge. Good teaching is not simply adding technology to the existing teaching and content domain. Rather, the introduction of technology causes the representation of new concepts and requires developing sensitivity to the dynamic, transactional relationship between all three components suggested by the TPACK framework.

In conclusion, this knowledge is different from knowledge of a disciplinary expert, or a technology expert and also from the general pedagogical knowledge shared by teachers across disciplines. In other words, TPACK represents what teachers need to know about technology in education and its value in subject matter instruction.

\section{Literature Review}

Since its formal introduction as a theoretical concept, TPACK has been transformed to a useful framework to aid ICT integration in school practice. The TPACK framework offers opportunities for looking at a complex phenomenon like technology integration in ways that are now amenable to analysis and development. In addition, it offers several possibilities for promoting research in teacher education (Lee \& Tsai, 2010), guiding pre-service teachers' education (So \& Kim, 2009) and in-service teacher professional development (Koehler et al., 2007; Koehler \& Mishra, 2009; Niess, 2005; Doering et al., 2009), and supporting teachers to integrate ICT in their classrooms (Voogt et al., 2009).

The TPACK model offers substantive promise for improving teachers' preparation to support productive technology integration in their teaching. Although this framework appears as an elegant and simple construct, in both textual and graphical forms, it is complex to comprehend and apply it in educational settings. The implementation of this framework in teacher education has been limited, in large part, to the original TPACK theorists' own experiments with graduate student seminars. This may be due to the fact that the framework has largely remained in the theoretical realm with no clear method for implementation or evaluation Cox $(2008$, p. 19). While Mishra and Koehler have provided definitions of each construct that articulate to some degree the centers of these constructs (Mishra \& Koehler, 2006; Koehler et al., 2007), the boundaries between them are still quite fuzzy, thus making it difficult to categorize borderline cases (Cox 2008, p.22). Following, Aggeli and Valanides (2009) argue that the conceptualization of TPACK needs further theoretical clarity. Their criticism is mainly focused on the current form of TPACK, which does not make explicit the connections among content, pedagogy, and technology and appears to be too general, primarily because it does not deal explicitly with the role of tool affordances in learning. 
Previous research indicates that to reveal the complex mesh of the interrelations between content, technology, and pedagogy in teaching practice is not an easy task. This creates a need to enhance the theoretically sound TPACK framework. This paper has the ambition to extend the knowledge of teachers' perception and willingness to adopt TPACK model by embodying this framework in authentic learning activities in their coursework.

\section{Project Overview}

\section{Description of the Project}

Technology integration in the schools is considered to be a significant national priority for the Greek educational system which is further supported by EU policy. In this framework, a new ambitious initiative, aiming at teachers acquiring basic knowledge and skills towards integration of ICT in the classroom, was established on 2007. The first phase of this programme aimed at the education of 400 teacher trainers which were selected on their degrees, teaching experience, and ICT qualifications. This phase was administered in five Greek Universities which established specific University Teacher Training Centres (UTTC) supported by highly experienced staff. Teacher trainers were divided in four groups in relation to their specialty, e.g. preschool and primary teachers, as well as three groups of secondary education teachers, namely literacy, mathematics and science teachers).

The coursework lasted 350 hours in total, divided into six hours duration lessons per day which were spread in an academic semester (approximately four months). The curriculum content comprised of two parts:

General theory modules: The lessons of this part lasted 170 hours in total and were common for the various teacher trainers' specialties. The models were described as Pedagogy, Learning Theories, ICT in Education, ICT tools (development ICT knowledge and skills), and Teacher Training Methods.

ICT in science education: Teacher trainers were divided in separate groups according to their subject matter. They received instruction in combination to extended individual and collaborative coursework in the computer laboratory. The second part of the project coursework lasted 180 hours in total. It comprised of separate modules focused on science education principles, educational software and tools for science education, subject matter learning scenarios and students' learning activities, development of novel-original learning scenarios and learning activities by the teachers.

\section{The UTTC at the University of Patras}

The design and research context presented here concerns science teacher trainers' preparation in the UTTC established at the University of Patras, where the author was the co-ordinator of the science education dimension of the project. The second part of the project coursework, 180 hour in total, was designed and coordinated by the author using the TPACK framework. The participants were four science teachers' chosen to attend to the project on a voluntary basis after their request through an open call for participation. Three of them had an academic degree in Physics and one in Chemistry. One teacher had a $\mathrm{PhD}$ in science education. Their teaching experience was ranging from 10 to 25 years, in upper and lower secondary education.

\section{Developing a TPACK Curriculum for Science Teachers'Trainers}

Science education constitutes a privileged subject matter when considering ICT integration and the related issues to enhance teachers' instructional potentialities and students' active engagement and learning opportunities. There is a range of efficient educational environments and applica- 
tions available for science education (e.g. simulations and modeling tools, microcomputer based laboratories (MBL), Web resources and environments, spreadsheets and databases, etc.) which offer a great variety of affordances for both students and teachers. The educational potential of ICT-based learning environments for science education has been advocated by many researchers (Jimoyiannis \& Komis, 2001; Webb, 2005).

Developing TPACK in science education requires a curricular system that would reveal the complex, multi-dimensional relationships by treating all three components in an epistemologically and conceptually integrated manner. The first step in our attempt to design a science teacher preparation program, based on the TPACK approach, was to clarify the constitutional components and make explicit connections among science (content), pedagogy, and technology in a meaningful and realistic context for secondary education. Following we give a brief description of the elements and how they used to guide the development of a coherent curricular system for teachers' education.

Pedagogical Content Knowledge: The PCK science corpus includes pedagogical strategies and techniques, representation and formulation of scientific concepts, knowledge of what makes those concepts difficult or easy to learn, knowledge of students' misconceptions, prior knowledge or cognitive difficulties, knowledge of students' theories of epistemology etc.

Technological Content Knowledge: The TCK in science incorporates issues of how science subjects are transformed by the specific technological environments. For example, the changes in the nature of science technology brings, new methods and tools used to solve science problems, modeling methods in science, the use of simulation software in physics etc..

Technological Pedagogical Knowledge: The TPK in science includes the knowledge of how technology can support specific pedagogical strategies in the classroom; for example, fostering inquiry or collaborative learning. Table 1 presents the main components we have identify to describe and specify the Technological Pedagogical Content Knowledge in science education.

Table 1: Technological Pedagogical Content Knowledge in science education

\begin{tabular}{ll}
\hline TPACK components & Knowledge components \\
\hline Pedagogical Content Knowledge & - Scientific Knowledge \\
- Science Curriculum \\
- Transformation of Scientific Knowledge \\
- Students' learning difficulties about spe- \\
- cific scientific fields \\
- Learning Strategies \\
- General Pedagogy \\
- Educational context \\
- Resources and tools available for science \\
- subjects \\
- Operational and technical skills related to \\
- specific Scientific Knowledge \\
- Transformation of Scientific Knowledge \\
- Transformation of Scientific Processes \\
- ICT-based learning strategies \\
- Fostering scientific inquiry with ICT \\
- Supporting information skills \\
- Student scaffolding \\
- Handling students' technical difficulties \\
\hline
\end{tabular}




\section{The TPACK Model for Science Education}

The second part of the project coursework was planned to follow a new mode for teacher preparation determined by an integrated framework combining TPACK model and authentic learning approach (Herrington \& Kervin, 2007). Considering that teachers are willing to learn and develop new skills related to their instruction through designing authentic activities, i.e. learning activities that are easily implemented and integrated in classroom settings. Therefore, teachers engaged in solving meaningful instruction problems through authentic ICT-based learning scenarios and activities with a sound pedagogical background. There was little direct instruction about particular software or tools during these courses. More common were spontaneous and short tutorial sessions driven by the immediate requirements of the group to cover the needs of the project.

We followed a problem-based approach, which shifts the focus from content learning towards problem solving as it provides a more realistic context for the teachers. This was a learnercentered approach which used a design framework covering planning, developing, evaluating and revising ICT-based learning and activities. The instructors rarely suggested or required the use of any specific technology; the emphasis on design required teachers to propose software and hardware solutions to their specific contexts and problems.

Furthermore, participants were exposed to detailed discussions of the pedagogical uses of various ICT tools (simulations, modeling tools, spreadsheets, MBL settings, scientific Web resources, ICT-based projects, WebQuests, Web 2.0 applications etc.) by identifying topics of special interest, e.g. science curriculum, transformation of abstract scientific concepts through simulations, learning and teaching strategies etc.

There are four distinct goals to this approach:

- to provide participants with stable representations of the various dimensions of the TPACK model and a meaningful understanding of the benefits and the barriers in applying TPACK in science classroom settings;

- to allow science teacher educators to move beyond oversimplified approaches and views of technology as an "add-on" element in classroom contexts and to focus upon the connections among technology, content, and pedagogy;

- to develop teacher educators' knowledge, skills and abilities to identify what type of technologies and how they could be integrated in school practice to enhance students' development in science education;

- to promote collaboration with colleagues to enhance their own learning and teaching to develop TPACK knowledge, both as learners and as teachers.

\section{Project Outcomes}

\section{Data Collection}

The overall purpose of the project was to enhance science teachers' knowledge and skills by developing a TPACK framework for their preparation. Specifically, the aims were to improve teachers' knowledge, skills and abilities to integrate ICT in science classroom, and to promote their use of ICT-based interventions and strategies promoting conceptual change during classroom practice.

Data about science teacher trainers were mainly collected through the transcripts of in-depth, audio-recorded, semi-structured interviews carried out by the researcher, at the end of the program, with all participants. The research questions aimed at a deeper investigation of 
- the representations and perceptions teachers developed about the various dimensions of TPACK model

- the knowledge, skills and abilities to integrate technology into science instruction the teachers believe that they have developed after their participation in the program

- the difficulties they expect to face at during their efforts to integrate ICT in science classroom in secondary schools.

\section{Main Implications}

Three major themes that might provide insight into teachers' experiences, perceptions and ideas about TPACK model and its impact on ICT integration in the schools have been identified and are presented here. These are linked to the research objectives above.

\section{Teachers' Representations and Perceptions of the TPACK model}

The first project objective was to implement a model that could act as an integrated framework for preparing science teachers to effectively integrate ICT in science classroom settings. Data from the interviews indicated that the participants developed stable and convincing representations about TPACK with respect to their subject matter, and a meaningful understanding of its value in science education. All the participants reported an increased willingness and confidence in their ability to apply ICT in their own instruction. Indicative are the following quotes:

\footnotetext{
"This program helped me to perceive and develop a totally different view for instruction... It is very important that there exists a sound theory behind all this things; that technology steps on certain theories and it should be applied under a certain framework in order to be efficient in practice."

"I learned too many things from this program though I used existing software for science subjects at a competent level. I was not aware about pedagogy and its value in using ICT in the classroom... I think that this program was beneficial and had a positive impact to me. I believe that the key point was the connection between theory and practice."

"The pedagogical dimension of the project was very important for me, not only because I heard a lot of things for the first time. This program game me a different lens to see my instruction... In general, I though that I was very competitive with ICT. Every day I use computers and the Internet. But I faced at issues that I did not know and I could not imagine that exist!! Hence, I have a different view about technology and how it can be used for educational purposes."
}

\section{Teachers' Perceived Knowledge and Skills to Integrate Technology into Science Instruction}

Participants reported in the final survey a change in their rationales for using ICT in science classroom. Data from the interviews indicated that all participants developed increased TPACK knowledge and skills with respect to their subject matter. Rather than primarily viewing technology integration through a simple skill-based lens (e.g. presentation of simulations or other tools through a video-projector) the program participants noted increased abilities to effectively integrate ICT into science content and curriculum (e.g. students engagement in inquiry etc.).

Indicative are the following quotes:

"I was familiar with some software tools before entering the project; but I used to view them as a confirmation medium of certain physical phenomena or processes, and not as a tool to support students' learning ..." 
"I had used many of that software in my classroom but in a different way; rather as a demonstration tool... I am now convinced that this approach will offer so many things to the students. It will not offer opportunities for discovery and constructive learning. Every student should be engaged and should work on his own computer... Hence, I have changed my view of how to use ICT in the classroom."

"Although most of the pedagogical knowledge was not new for me, this program was useful not only because it helped me to clarify many aspects... The strong point of the approach followed in this program is that it strengthens our sensitivity, as educators, to see the instructional way from the other side, the students' side; that is to say from learning to teaching..."

\section{Main Difficulties to Integrate ICT in Science Classroom}

The last research objective was to identify teachers' main difficulties to integrate ICT in science classroom. They consider TPACK as a promising model which effectively combines theoretical and practical aspects of this issue. Moreover, teachers' views and perceptions are strongly influenced by broader contextual parameters of the educational system, namely

- the need to cover an extended content set by the science curriculum and the textbooks;

- the restrictions posed into instructional practices by the science textbooks;

- the need to prepare students for the final exams;

- the lack of time to prepare learning activities focused on their students' needs;

- the inherent school resistance to changes, which forces most of the teachers to conform their instruction to the established school culture and practices.

\section{Epilogue}

This paper elaborated on the design of the TPACK framework for science education and the development of the course sessions in a program aiming at teachers' preparation to integrate ICT in science classrooms. The effects of the program on participants' perceived skills and abilities on TPACK, as well as their views about the value of TPACK in integrating ICT in the science classroom were described. In addition, this exploration reveals the importance placed by the participants on the educational context determining the instruction of science subject matters in the schools.

Teachers' development on TPACK requires continued and authentic learning experiences with opportunities for teaching in real class situations, and follow-up reflection and feedback. Teachers' TPACK development continues beyond training programmes and should be an integral part of in-service teacher professional development.

Future initiatives and professional development programs should focus on coupling changes in teachers' pedagogical cultures and philosophies for teaching and learning with their training on how to use appropriate ICT tools with their students. Direct instruction that focuses on one of the TPACK components at a time would be relatively ineffectual in helping teachers develop an understanding of how these knowledge bases relate to each other.

Undoubtedly, there are a lot of things we do not yet know about TPACK, its development and its adoption by the teachers. In addition, the high level of relation of TPACK with respect to subject matter makes it difficult to determine how best to prepare teachers to cultivate this model and integrate ICT in everyday school practice. The need to evaluate the effectiveness of the methods used in teacher technology preparation programs, and to enhance our knowledge about the strong and weak sides of TPACK model, is an open and very interesting research problem. 


\section{References}

Angeli, C., \& Valanides, N. (2009). Epistemological and methodological issues for the conceptualization, development, and assessment of ICT-TPCK: Advances in technological pedagogical content knowledge (TPCK). Computers \& Education, 52, 154-168

Cox, S. (2008). A conceptual analysis of technological pedagogical content knowledge. Unpublished doctoral dissertation. Brigham Young University.

Doering, A., Scharber, C., Miller, C., \& Veletsianos, G. (2009). GeoThentic: Designing and assessing with technology, pedagogy, and content knowledge. Contemporary Issues in Technology and Teacher Education, 9(3), 316-336.

Doering, A., Veletsianos, G., Scharber, C., \& Miller, C. (2009). Using the Technological, Pedagogical, and Content Knowledge Framework to design online learning environments and professional development. Journal of Educational Computing Research, 41(3), 319-346.

Herrington, J., \& Kervin, L. (2007). Authentic learning supported by technology: Ten suggestions and cases of integration in classrooms. Educational Media International, 44(3), 219-236.

Jimoyiannis, A. (2008). Factors determining teachers' beliefs and perceptions of ICT in education. In A. Cartelli \& M. Palma (Eds.), Encyclopedia of information communication technology (pp. 321-334), Hershey, PA: IGI Global.

Jimoyiannis, A., \& Komis, V. (2001). Computer simulations in teaching and learning physics: A case study concerning students' understanding of trajectory motion. Computers \& Education, 36(2), 183-204.

Jimoyiannis, A., \& Komis, V. (2006). Exploring secondary education teachers' attitudes and beliefs towards ICT in education. THEMES in Education, 7(2), 181-204.

Jimoyiannis, A., \& Komis, V. (2007). Examining teachers' beliefs about ICT in education: Implications of a teacher preparation programme. Teacher Development, 11(2), 149-173.

Koehler, M. J., \& Mishra, P. (2009). What is technological pedagogical content knowledge? Contemporary Issues in Technology and Teacher Education, 9(1), 60-70.

Koehler, M., J., Mishra, P. \& Yahya, K. (2007). Tracing the development of teacher knowledge in a design seminar: Integrating content, pedagogy and technology. Computers \& Education, 49, 740-762.

Lee, M.-H., \& Tsai, C.-C. (2010). Exploring teachers' perceived self efficacy and technological pedagogical content knowledge with respect to educational use of the World Wide Web. Instructional Science, $38(1), 1-21$.

Niess, M. L. (2005). Preparing teachers to teach science and mathematics with technology: Developing a technology pedagogical content knowledge. Teaching and Teacher Education, 21, 509-523.

Mishra, P. \& Koehler, M. J. (2006). Technological Pedagogical Content Knowledge: A framework for teacher knowledge. Teachers College Record, 108(6), 1017-1054.

Rogers, E. M. (1995). Diffusion of innovation (4th ed.). New York: Free Press.

Russel, A. L. (1995). Stages in learning new technology: Naïve adult email users. Computers \& Education, 25(4), 173-178.

Shulman, L. S. (1986). Those who understand: knowledge growth in teaching. Educational Researcher, $15(2), 4-14$.

So, H.-J., \& Kim, B. (2009). Learning about problem based learning: Student teachers integrating technology, pedagogy and content knowledge. Australasian Journal of Educational Technology, 25(1), 101116.

Toledo, C. (2005). A five-stage model of computer technology integration into teacher education curriculum. Contemporary Issues in Technology and Teacher Education, 5(2), 177-191. 
Voogt, J., Tilya, F., \& van den Akker, J. (2009). Science teacher learning of MBL-supported studentcentered science education in the context of secondary education in Tanzania. Journal of Science Education and Technology, 18, 429-438.

Waite, S. (2004). Tools for the job: A report of two surveys of information and communications technology training and use for literacy in primary schools in the West of England, Journal of Computer Assisted Learning, 20, 11-20.

Webb, M. E. (2005). Affordances of ICT in science learning implications for an integrated pedagogy, International Journal of Science Education, 27(6), 705-735.

Zhao, Y., \& Bryant, F.-L. (2006). Can teacher technology integration training alone lead to high levels of technology integration? A qualitative look at teachers' technology integration after state mandated technology training. Electronic Journal for the Integration of Technology in Education, 5, 53-62.

\section{Biography}

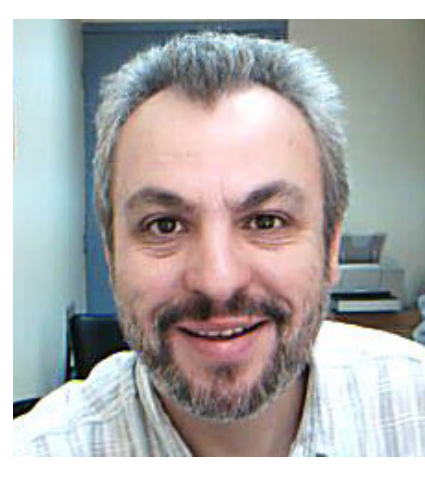

Dr. Athanassios Jimoyiannis is an associate professor of Science and ICT in Education at the Department of Social and Educational Policy, University of Peloponnese, in Greece. Prior to his current position he has been an assistant professor at the Department of Preschool Education, University of the Aegean. His current research interests include e-learning and ICT in education, teachers' preparation about ICT in education, computer science education and science education. He is a co-editor of the international journal THEMES in Science and Technology Education. He is also a member of the Scientific Review Board in various international journals and conferences in the areas of e-learning and ICT in education. 